\title{
Influência do excesso de nitrogênio amoniacal no tratamento de efluente têxtil em reator de bateladas sequenciais com Aspergillus niger AN 400
}

\author{
Influence of excess nitrogen in the treatment of the textile effluent in \\ sequential batch reactors with Aspergillus niger AN 400

\begin{abstract}
Karla Mayara Lima da Silva', Carlos Ronald Pessoa Wanderley², Glória Marinho³, Jéssica Cavalcante de Oliveira ${ }^{4}$, Andreza Dnarla Oliveira dos Santos ${ }^{5}$, Kelly Rodrigues ${ }^{6}$
\end{abstract}

\section{RESUMO}

Agua residuária têxtil foi tratada com Aspergillus niger AN 400 em reator de bateladas sequenciais, em ciclos de $48 \mathrm{~h}$ para avaliar o efeito de fonte adicional de nitrogênio sobre a eficiência do sistema alimentado com efluente diluído (10\% v/v) e glicose (3 g.. $\left.L^{-1}\right)$. O afluente recebeu fonte adicional de nitrogênio (etapa I), acarretando em excesso de nitrogênio amoniacal (192 mg.L'1) no meio, resultando em remoção de matéria orgânica de 85\%, porém em apenas 55\% de remoção de corante. Ao se diminuir a concentração média de amônia para 98 mg.L.-1 (etapa II), a remoção de corante (83\%) passou a ser superior à de matéria orgânica, de 69\%, mostrando o efeito negativo de concentrações elevadas de amônia sobre o sistema, favorecendo ainda o crescimento de bactérias, o que provavelmente inibiu a produção de enzimas fúngicas e contribuiu para a perda de eficiência na remoção de corante e formação de subprodutos. Palavras-chave: Índigo Carmim; bateladas sequenciais; efluente têxtil; fungos.

\begin{abstract}
Textile wastewater was treated by Aspergillus niger AN 400 in sequential batch reactor, which was operated in cycles of $48 \mathrm{~h}$ in order to evaluate the effect of an additional source of nitrogen on the system's efficiency, which was fed with effluent diluted (10\% v/v) and glucose ( $\left.3 \mathrm{~g} . \mathrm{L}^{-1}\right)$. The influent received addition of an external source of nitrogen (phase $\mathrm{I}$ ), in which there

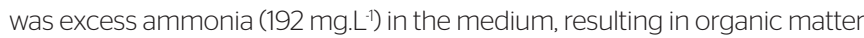
removal of $85 \%$, but in only $55 \%$ removal of dye. In the phase II, when the average concentration of ammonia in the medium was lower (98 $\mathrm{mg} . \mathrm{L}^{-1}$ ), removal of dye (83\%) became higher than that of organic matter (69\%), showing the negative effect of high concentrations of ammonia over the system and favoring the growth of bacteria, which probably inhibit the production of fungal enzymes and contributed to the loss of efficiency in the removal of dye and the formation of byproducts.
\end{abstract}

Keywords: Carmim Indigo, sequential batch, textile effluent, fungi.

\section{INTRODUÇÃO}

As indústrias têxteis possuem relevante importância na economia mundial e, no Brasil, tem se destacado como uma das principais em geração de empregos e faturamentos, uma vez que empregam mais de 1,7 milhões de trabalhadores, e juntas tem um faturamento anual de US\$ 47 bilhões, como apresentado em Alves (2013).
Entretanto, apesar das divisas econômicas geradas, as atividades decorrentes do processamento têxtil são caracterizadas pelo consumo intenso de água e de corantes, cuja presença traz como consequência a geração de efluentes com elevado nível de coloração (KILIÇ et al., 2007).

$\mathrm{O}$ uso de corantes no processo têxtil tem por função conferir cor à fibra, sobre condições pré-estabelecidas, sendo substâncias químicas

'Tecnóloga Ambiental. Mestre em Tecnologia e Gestão Ambiental pelo Programa de Pós-graduação em Tecnologia e Gestão Ambiental do Instituto Federal de Educação Ciência e Tecnologia do Ceará (IFCE) - Fortaleza (CE), Brasil.

²Engenheiro Civil. Mestre em Saneamento Ambiental pela Universidade Federal do Ceará (UFC). Professor efetivo do Curso de Engenharia Ambiental do IFCE - Fortaleza (CE), Brasil. ${ }^{3}$ Farmacêutica. Doutora em Hidráulica e Saneamento pela Escola de Engenharia de São Carlos - Universidade de São Paulo (EESC-USP). Professora efetiva do Departamento de Química e Meio Ambiente do IFCE - Fortaleza (CE), Brasil.

${ }^{4}$ Aluna do curso de graduação em Tecnologia Ambiental do IFCE. Bolsista de trabalho em pesquisa científica do IFCE - Fortaleza (CE), Brasil.

${ }^{5}$ Aluna do curso de graduação em Tecnologia Ambiental do IFCE. Bolsista de iniciação científica do Conselho Nacional de Desenvolvimento Científico e Tecnológico (CNPq) Fortaleza (CE), Brasil.

${ }^{6}$ Engenheira Civil. Doutora em Hidráulica e Saneamento pela EESC-USP. Professora efetiva do Departamento de Química e Meio Ambiente do Instituto Federal de Educação Ciência e Tecnologia do Ceará (IFCE) - Fortaleza (CE), Brasil.

Endereço para correspondência: Kelly Rodrigues - Rua Virgílio Paes, 2323, Cidade dos Funcionários - 60822-465 - Fortaleza (CE), Brasil - E-mail: kellyarpessoa@gmail.com Recebido: 19/11/12 - Aceito: 24/05/15 - Reg. ABES: 106578 
solúveis, não abrasivas e com capacidade elevada de absorção luminosa, nos comprimentos de onda entre 400 e $800 \mathrm{~nm}$. Porém, a mesma solubilidade que confere aos corantes a capacidade de interagir com a superfície do material, pode amplificar seu efeito tóxico (SARON \& FELISBERTI, 2006), além de interferir na transparência da água, mesmo que em concentração baixa, pois a detecção de cor no meio é visível em concentrações tão baixas quanto 1 ppm (ZANONI \& CARNEIRO, 2001).

Desta forma, a presença de efluentes coloridos em corpos d'água acarreta uma problemática ambiental grave, por afetar a estética, a transparência da água, o processo fotossintético pelo fitoplâncton com a diminuição da penetração da luz - e consequente diminuição do oxigênio dissolvido e ainda a solubilidade de outros gases presentes nos corpos d'água (COUTO, 2009).

Outro aspecto a ser considerado é em relação à saúde pública, pois a ingestão de água contendo corantes pode acarretar, no sistema digestivo, a formação de produtos mais nocivos do que o próprio corante por possuírem propriedades cancerígenas e de alto poder mutagênico (ANASTÁCIO FERRAZ, 2008). Essas características danosas são endossadas por Bolzon (2007), que alertou para os problemas decorrentes do contato entre corantes indigoides - de valor econômico elevado e de grande aplicação no setor industrial para o tingimento de roupas (blue jeans) - e seres humanos, ratificando a natureza carcinogênica desses compostos, que podem conduzir a toxicidades agudas e afetar o sistema reprodutivo, neurológico e o crescimento do indivíduo.

Mediante esse contexto, nos últimos anos, regulamentações rigorosas têm sido estabelecidas em muitos países em relação ao descarte de efluentes coloridos, especialmente nos países desenvolvidos e em desenvolvimento, no que diz respeito à remoção de cor dos efluentes industriais. Sua aplicação continuará a assegurar que indústrias têxteis e de outros corantes tratem seus efluentes para que se ajustem aos padrões requeridos, minimizando o impacto ambiental e danos à saúde humana (ANJANEYULU; CHARY; RAJ, 2005).

Dentre as múltiplas estratégias aplicadas para a eliminação de corantes têxteis, a utilização de fungos demonstra ser uma alternativa viável para a remoção desses compostos no meio ambiente (BANAT et al., 1996; GIANFREDA \& RAO, 2004), em vista de não resultar na presença de aminas aromáticas não degradáveis, como ocorre quando do emprego de processos anaeróbios (VAN DER ZEE \& VILLAVERDE, 2005; ISIK \& SPONZA, 2005), e também pela existência de dados promissores apresentados em várias pesquisas, como as de Sanghi et al. (2009); Yang et al. (2009) e Senthilkumar, Perumalsamy e Janardhana Prabhu (2014), entre outros.

Sanghi et al. (2009) estudaram a remoção de cor de efluente têxtil sintético pelo fungo Coriolus versicolor em reator em bateladas sequenciais. Na presença de 100 g.L.-1 do corante Remazol Violeta Brilhante foram testados diferentes cossubstratos: glicose $\left(10\right.$ g.L $\left.\mathrm{L}^{-1}\right)$, sabugo de milho $\left(5\right.$ g.L $\left.\mathrm{L}^{-1}\right)$ e lactose $\left(5\right.$ g.L $\left.\mathrm{L}^{-1}\right)$. Foram obtidas remoções de matéria orgânica, em termos de demanda química de oxigênio (DQO), variando de 50 a 60\%.
A remoção de cor foi elevada, chegando a 95 e $94 \%$, respectivamente, quando do uso da glicose e do sabugo de milho, sendo esse percentual menor (45\%) quando a lactose foi o cossubstrato adicionado ao meio.

Yang et al. (2009) utilizaram reator de leito fixo e escoamento contínuo inoculado com fungos para tratar efluente têxtil in natura, operado com tempo de detenção hidráulica $(\mathrm{TDH})$ de $12 \mathrm{~h}$, com adição de 0,5 g.L.-1 de glicose e de 0,1 g.L. - $^{-1}$ de $\left(\mathrm{NH}_{4}\right)_{2} \mathrm{SO}_{4}$. Foi alcançada remoção de cor de $89 \%$. Houve predominância de Candida sp. no biofilme em relação à população bacteriana a partir da contagem do número de colônias, com proporção mínima de 6,8:1 (fungos:bactérias), constatando-se a não inibição da atividade enzimática dos fungos.

Senthilkumar, Perumalsamy e Janardhana Prabhu (2014) avaliaram a remoção de cor de meio contendo 1 g.L $\mathrm{L}^{-1}$ do corante Amido Black 10B por Phanerochaete chrisosporyum. A glicose foi o cossubstrato adicionado ao meio nas concentrações de 0,$05 ; 0,1 ; 0,5 ; 1$ e $2 \%$ (w/w). Também foi utilizada mistura de fosfato dihidrogênio de amônio e cloreto de amônio, na razão de 5:1, a qual foi adicionada nas concentrações de 0,01; 0,05; 0,1; 0,5 e 1\% (w/w). A maior eficiência de remoção de cor (97\%) ocorreu quando da adição de 0,5 g.L $L^{-1}$ de glicose e de $0,5 \%$ da fonte de nitrogênio, em seis dias de batelada.

Assim, tendo em vista o potencial dos fungos filamentosos para o tratamento de efluentes têxteis em reatores biológicos, esta pesquisa foi desenvolvida com o propósito de remover o corante Índigo Carmim de efluente têxtil in natura diluído a $10 \%$ (v/v), utilizando reator em bateladas sequenciais (RBS) inoculado com biomassa imobilizada de Aspergillus niger AN 400, verificando a influência da presença e ausência de fonte adicional de nitrogênio no meio têxtil.

\section{METODOLOGIA}

\section{Água residuária têxtil in natura diluída a 10\% (v/v)}

A água residuária in natura foi coletada do tanque de equalização de uma indústria têxtil localizada na região Metropolitana de Fortaleza, Ceará, e continha em sua composição o corante Índigo Carmim, com estrutura química representada na Figura 1. A coleta do efluente foi

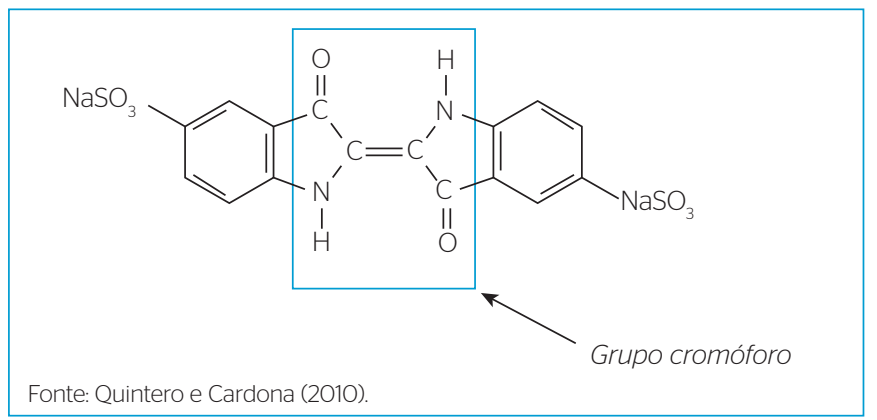

Figura 1 - Estrutura molecular do corante têxtil Índigo Carmim. 
realizada por meio de um frasco de polietileno de $5 \mathrm{~L}$, previamente descontaminado com ácido clorídrico a 10\% (v/v).

A água residuária têxtil in natura que preencheu o reator biológico foi diluída a $10 \%(\mathrm{v} / \mathrm{v})$ e foi, posteriormente, acrescida de macronutrientes, na seguinte composição (em g.L-1 $)$ : $\left(\mathrm{NH}_{4}\right)_{2} \mathrm{SO}_{4}$ $(0,2), \mathrm{NaNO}_{3}(1,0), \mathrm{mgSO}_{4}(0,25), \mathrm{K}_{2} \mathrm{HPO}_{4}(0,2), \mathrm{CaCl}_{2} \cdot 2 \mathrm{H}_{2} \mathrm{O}(0,01)$, $\mathrm{CuSO}_{4} .7 \mathrm{H}_{2} \mathrm{O}(0,08), \mathrm{H}_{2} \mathrm{MoO}_{4}(0,05), \mathrm{MnSO}_{4} \cdot 5 \mathrm{H}_{2} \mathrm{O}(0,05), \mathrm{Fe}_{2}(\mathrm{SO} 4)_{3}$ $(0,05), \mathrm{ZnSO}_{4} .7\left(\mathrm{H}_{2} \mathrm{O}\right)(0,04)$ e $1 \mathrm{~mL} \cdot \mathrm{L}^{-1}$ de solução de contendo micronutrientes (solução de Vishniac).

$\mathrm{O}$ pH do meio aquoso in natura foi previamente ajustado para 5, com ácido sulfúrico PA para fornecer ao Aspergillus niger $\mathrm{pH}$ ótimo para seu metabolismo (GRIFFIN, 1994).

\section{Preparo do inóculo}

A espécie utilizada para o tratamento foi o Aspergillus niger AN 400 e o inóculo foi obtido por meio da produção de esporos, cultivados em placas de Petri esterilizadas, contendo meio de cultura Agar-Saboraud a $30^{\circ} \mathrm{C}$, tendo sido o meio previamente esterilizado em autoclave a $121^{\circ} \mathrm{C}$, durante 15 minutos.

As placas inoculadas com fungos permaneceram por cinco dias em incubadora microbiológica à temperatura de $28^{\circ} \mathrm{C}$, tendo-se, ao final desse período, observado o crescimento dos esporos por toda a placa, de modo que eeses foram então removidos, adicionando-se em cada placa $5 \mathrm{~mL}$ de solução Tween 80 , e transferidos para tubos de ensaio.

Posteriormente, $50 \mu \mathrm{L}$ da suspensão de esporos foi agitada em vórtex com adição de $950 \mu \mathrm{L}$ de solução Tween 80 , retirando-se então $20 \mu \mathrm{L}$ dessa mistura para leitura do número de esporos por $\mathrm{mL}$, fazendo uso de câmara de Neubauer, em microscópico óptico com aumento de 400x em 16 campos.

\section{Imobilização da biomassa em meio suporte}

A espécie Aspergillus niger AN 400 foi imobilizada em espuma de poliuretano, cortada em cubos de $1 \mathrm{~cm}$ de aresta, fazendo uso de frascos Erlenmeyer de $250 \mathrm{~mL}$, contendo meio de crescimento, o qual era constituído por (mg.L $\left.\mathrm{L}^{-1}\right)$ : glicose (5000), sulfato de alumínio $(0,8)$; nitrato de sódio (4); sulfato de magnésio (1); fosfato de potássio dibásico anidro $(0,8)$; cloreto de cálcio $(0,04)$; sulfato de cobre $(0,32)$; ácido molibídico $(0,2)$; sulfato de manganês $(0,2)$; sulfato férrico $(0,2)$; e sulfato de zinco $(0,16)$. Foi ainda adicionado ao meio a solução de Vishiniac $\left(1 \mathrm{~mL} \cdot \mathrm{L}^{-1}\right)$.

Quinze gramas de espumas foram previamente esterilizadas em autoclave por $20 \mathrm{~min}$ a $121^{\circ} \mathrm{C}$ e depois colocadas em saquinhos de polietileno que foram distribuídos em 3 Erlenmeyers com volume útil de $250 \mathrm{~mL}$, cada qual contendo $5 \mathrm{~g}$ da espuma juntamente com $150 \mathrm{~mL}$ do meio de crescimento.

Em seguida, inoculou-se a suspensão de esporos, obtida do preparo do inóculo, na concentração de $2 \times 10^{6}$ esporos. $\mathrm{mL}^{-1}$, sendo o procedimento realizado próximo ao bico de Bunsen, para evitar contaminação.
Os Erlenmeyers foram mantidos em uma mesa agitadora horizontal, sob agitação de $150 \mathrm{rpm} \mathrm{e} \pm 28^{\circ} \mathrm{C}$, durante 16 dias, ressaltando-se que dentro desse período, a cada $48 \mathrm{~h}$, o meio contido no interior do reator era substituído por um meio recém preparado. Após a etapa de imobilização, as espumas foram transferidas para o reator em batelada para a partida do mesmo.

\section{Reator em bateladas sequenciais}

Foi montado reator aeróbio, com volume total de $5 \mathrm{~L}$ e volume reacional de $4 \mathrm{~L}$, operado em regime de bateladas sequenciais, com a biomassa de Aspergillus niger AN 400, imobilizada em espumas de poliuretano.

$\mathrm{O}$ reator era de vidro e foi coberto por saco preto de polietileno, para evitar degradação fotolítica. $\mathrm{O}$ ar era fornecido por meio de mini-compressor, na vazão de 150 L.h.' ${ }^{-1}$.

A alimentação do reator com a água residuária in natura diluída a $10 \%(\mathrm{v} / \mathrm{v})$ era feita no início de cada semana e o mesmo operado em ciclos com tempo reacional de $48 \mathrm{~h}$. O experimento compreendeu um total de 43 ciclos, perfazendo 86 dias de operação.

Além disso, a glicose ( 3 g.L $\left.\mathrm{L}^{-1}\right)$ foi adicionada ao meio como fonte primária de carbono, uma vez que o próprio corante Índigo também representava outra fonte de carbono, porém de maior complexidade. A partir do $25^{\circ}$ ciclo, foi suspensa a adição de fonte adicional de nitrogênio - sulfato de amônia e nitrato de sódio - ao efluente diluído, constituindo assim a etapa I ( $1^{\circ}$ ao $24^{\circ}$ ciclo) e a etapa II $\left(25^{\circ}\right.$ ao $43^{\circ}$ ciclo $)$.

Foi adicionado ainda o antibiótico Megacilin Super Plus, na concentração de 0,12 g.L $L^{-1}$, para minimizar a contaminação por bactérias.

\section{Análises físico-químicas}

As análises físico-químicas foram realizadas em amostras da água residuária diluída, do afluente e efluente do reator. Foram efetuadas as determinações das variáveis: corante, DQO bruta e dissolvida e pH. Todos os métodos para determinação das variáveis mencionadas seguiram procedimentos descritos em APHA (2005), exceto a determinação de corante.

A determinação da concentração de corante foi realizada com base em Rodrigues et al. (2011), a partir da medida da absorção do grupo cromóforo do Índigo Carmim, no comprimento de onda $(\lambda)$ de $640 \mathrm{~nm}$, uma vez que o cromóforo é a estrutura responsável pela característica de coloração do corante.

Para se ter a relação entre a absorbância obtida e seu equivalente em termos de concentração de corante, foi construída curva de calibração, com o uso de soluções de concentrações conhecidas do corante Índigo Carmim, variando de 0 (branco) a 50 mg.L $\mathrm{L}^{-1}$. Antes da leitura, em espectrofotômetro, as amostras foram centrifugadas a $3.500 \mathrm{rpm}$, durante 15 minutos.

Desta forma, a partir dos dados de absorbância versus concentração de corante adicionado, pode ser obtida a equação que estabeleceu a relação entre concentração de corante equivalente e absorbância. A eficiência (E) de remoção de corante foi calculada conforme a Equação 1: 
$\mathrm{E}(\%)=100 \times(\mathrm{Co}-\mathrm{C}) / \mathrm{Co}$

Co: concentração afluente (mg.L-1);

C: concentração efluente (mg.L-1).

\section{Verificação de co-produtos da degradação via espectroscopia UV-Vis}

Foi realizado detalhamento espectroscópico das bandas de absorção do corante Índigo Carmim em amostras do efluente e afluente, visando verificar a possível formação de subprodutos resultantes da degradação do corante. Para tanto, foram executadas "varreduras" entre 200 e $800 \mathrm{~nm}$ das alíquotas em um espectrofotômetro UV-Vis (Thermo Evolution 100). O corante Índigo Carmim possui uma larga banda de absorção na região do visível (640 nm), referente ao seu grupo cromóforo $(-\mathrm{C}=\mathrm{C}$ - ligado a $\mathrm{CO}$ e $\mathrm{NH}$ no centro da molécula) e duas outras bandas de absorção na região do ultravioleta, uma em $205 \mathrm{~nm}$ e outra em $265 \mathrm{~nm}$, referentes à fração aromática do corante.

Devido aos problemas laboratoriais somente foram realizadas varreduras na etapa I, nos ciclos C16 e C19.

\section{Contagem das unidades formadoras de colônias de micro-organismos}

A determinação das unidades formadoras de colônias ocorreu no final das etapas I e II, procedendo-se à diluição em série da amostra do efluente de cada uma das etapas. Após a diluição, fez-se o plaqueamento em placas de Petri contendo meios seletivos: meio Martin, usado para a contagem de colônias de fungos, e meio nutriente-ágar, para contagem do número de colônias de bactérias.

O meio de Martin era composto de (g.L $\left.\mathrm{L}^{-1}\right): \mathrm{K}_{2} \mathrm{HPO}_{4}$ (1); peptona (5); $\mathrm{KH}_{2} \mathrm{PO}_{4}(0,5) ; \mathrm{mgSO}_{4} .7 \mathrm{H}_{2} \mathrm{O}(0,5)$; dextrose (10); extrato de levedura $(0,5)$; rosa bengala (0,033); ágar (18). Além disso, foi adicionado $3 \mu \mathrm{g} \cdot \mathrm{mL}^{-1}$ de estreptomicina, antibiótico usado para evitar contaminação do meio por bactérias. O meio nutriente-ágar possuía (g.L-1): bacto-agar (15); extrato de carne (2); peptona (5); $\mathrm{NaCl}(8)$.

Desta forma, a amostra do efluente $(10 \mathrm{~mL})$ foi misturada em $90 \mathrm{~mL}$ de solução salina $(0,89 \%)$ em tubos, os quais foram posteriormente agitados em vórtex por $10 \mathrm{~min}$. Então, alíquotas de $1 \mathrm{~mL}$ foram retiradas desses tubos e transferidas para $9 \mathrm{~mL}$ de solução salina e, dessa forma, o mesmo procedimento foi feito sucessivamente até obter concentrações de $10^{-2}, 10^{-3}$ e $10^{-4}$. Em seguida, as diluições em série obtidas foram plaqueadas nos meios seletivos de Martin e nutriente-ágar, com ajuda de alça de Drigalski.

\section{Ensaio de adsorção do corante no biofilme}

A quantidade de Índigo Carmim presente no biofilme foi estimada retirando-se um cubo contendo biomassa imobilizada do reator, após o último ciclo, sendo então transferido para Erlenmeyer de $250 \mathrm{~mL}$, adicionado de $100 \mathrm{~mL}$ de solução salina e pérolas de vidro. Em seguida, o conjunto foi submetido à agitação vigorosa para propiciar a remoção de biomassa do meio suporte. O meio foi então centrifugado a $3.500 \mathrm{rpm}$ e o sobrenadante foi separado da biomassa. O metanol foi utilizado como solvente para remover o corante adsorvido, de modo que $10 \mathrm{~mL}$ foram transferidos juntamente com a biomassa para tubos, permanecendo em contato durante $10 \mathrm{~min}$. Depois desse período, foi adicionado mais $5 \mathrm{~mL}$ de metanol, seguido de homogeneização e leitura espectrofotométrica a $640 \mathrm{~nm}$.

\section{Ensaio de adsorção no meio suporte}

Foi utilizado frasco de vidro de $2 \mathrm{~L}$, ao qual foram adicionados $15 \mathrm{~g}$ do material suporte previamente seco em estufa. Esse recipiente recebeu $1 \mathrm{~L}$ de água residuária diluída $(20 \% \mathrm{v} / \mathrm{v})$.

A capacidade máxima de adsorção do corante na espuma de poliuretano, empregada como material suporte, foi monitorada a partir da sua concentração inicial no meio durante um período de $1,83 \mathrm{~h}$, retirando-se amostras do meio a cada 10 minutos para determinação da concentração de saturação e a respectiva massa de corante adsorvida à mesma.

\section{RESULTADOS E DISCUSSÕES}

Na etapa I, a concentração média de corante no afluente foi de $10 \mathrm{mg} \cdot \mathrm{L}^{-1}$, variando de 3 a $20 \mathrm{mg} . \mathrm{L}^{-1}$, pois o efluente foi oriundo de processamento têxtil, apresentando alterações em função do tipo e quantidade de produto produzido, bem como de técnicas empregadas. Nessa etapa, foi observado decaimento da concentração inicial do Índigo Carmim, registrando-se remoção média do corante de 55\%, máxima de $97 \%$ (ciclo C24) e mínima de 3\% (ciclo C6).

É importante mencionar que, em metade dos ciclos operacionais da etapa I, a eficiência de remoção do Índigo Carmim não foi boa, ocorrendo ciclos em que as remoções foram inferiores à média registrada para a etapa (55\%) e outros em que não houve remoção do corante, nos quais a concentração do mesmo no efluente foi superior à do afluente (Figura 2). A perda da eficiência foi atribuída à suplementação do meio com os compostos nitrogenados, pois concentrações elevadas de nitrogênio amoniacal, como as encontradas no presente trabalho (192 mg. $\left.\mathrm{L}^{-1}\right)$, inibiram a assimilação do corante pelos fungos (KHELIFI et al., 2009; SANGHI; DIXIT; GUHA, 2006; SWAMY \& RAMSAY, 1999).

É importante mencionar que quando da remoção de corantes pelos micro-organismos, há a adsorção de parcela destes à parede da célula e/ou ao material suporte usado para imobilização da biomassa, seguida do processo de biodegradação (COULIBALY; GOURENE; AGATHOS, 2003) - no qual o poluente é incorporado ao material celular —, sendo que a parcela adsorvida poderá sofrer dessorção, em função do $\mathrm{pH}$ do meio, entre outros fatores que podem levar à liberação do corante fracamente ligado à superfície micelial e/ou do suporte (SINGH, 2006; WANG \& HU, 2008). 
De acordo com Debrassi, Largura e Rodrigues (2011), o acúmulo de corante no meio é propiciado pela competição por sítios de adsorção entre o corante e íons $\mathrm{OH}^{-}$e, conforme há o aumento do valor do $\mathrm{pH}$ no meio, o número de sítios carregados positivamente diminui, o que resulta na redução da adsorção do corante devido à repulsão eletrostática.

Na presente pesquisa, na etapa I, o valor médio do $\mathrm{pH}$ foi 8 (variando de 5,9 a 9), ao passo que na etapa II, esse valor foi de 5,6 (variando de 4 a 7,6). Os maiores valores de $\mathrm{pH}$ registrados na etapa I estariam relacionados com as reações de conversão de nitrato a nitrito pelos fungos, ocorrendo liberação de $\mathrm{OH}^{-}$, o que favorece a dessorção do poluente (GRIFFIN, 1994).

Quando o micélio está protonado, o que pode ocorrer em meio ácido, a velocidade de adsorção de corante tende a aumentar. Chaves et al. (2008), ao utilizarem biomassa morta de Aspergillus niger verificaram maior adsorção do corante quando a superfície do micélio estava protonada, após tratamento com solução ácida de $\mathrm{H}_{2} \mathrm{SO}_{4}$, e perda da capacidade biossortiva da massa micelial quando esta foi tratada com solução alcalina de $\mathrm{NaOH}$.

De fato, na etapa II, com os valores mais baixos de $\mathrm{pH}$, influenciados pela retirada da fonte externa de nitrogênio, houve, possivelmente, diminuição da tendência à dessorção do corante, com a produção de enzimas atuantes na degradação de corantes e outros poluentes sendo favorecida (KHELIFI et al., 2009; SWAMY \& RAMSAY, 1999). Isso foi evidenciado pela melhora nos percentuais de remoção do Índigo Carmim, com eficiência média de 83\%, máxima de 97\% (ciclos C26 e C40) e mínima de 69\% (ciclo C39). Nessa etapa, a concentração média de corante afluente foi de $10 \mathrm{mg} . \mathrm{L}^{-1}$, variando de 5 a $19 \mathrm{mg} . \mathrm{L}^{-1}$.

É importante mencionar que embora tenha sido observada a adsorção de corante ao material suporte $(0,064 \mathrm{~g})$ e no biofilme $(0,32 \mathrm{~g})$, perfazendo massa de corante adsorvida de $0,38 \mathrm{~g}$, essa parcela foi inferior à massa total de corante removido pelo reator $(2,11 \mathrm{~g})$, indicando que a via biológica foi o principal mecanismo de remoção do corante.

Na Figura 2 são apresentadas as varreduras realizadas no afluente e efluente dos ciclos C16 e C19, contatando-se diminuição na área relativa ao grupo cromóforo da molécula do corante Índigo Carmim, as quais foram de 51 e $57 \%$, respectivamente.

Nos ciclos C16 e C19, apesar de ter ocorrido ruptura da ligação química do grupo cromóforo, $-\mathrm{C}=\mathrm{C}-(\lambda=640 \mathrm{~nm})$, não houve a utilização efetiva do anel benzeno $(\lambda=205 \mathrm{~nm})$ que compõe a molécula do corante, tendo-se, no ciclo C16, obtido remoção muito pequena (Figura 2A), de apenas 4\%. Paralelamente, detectou-se acréscimo de compostos aromáticos no comprimento de onda de $\lambda=265 \mathrm{~nm}$.

Já no ciclo C19, registrou-se aumento do valor das absorbâncias para as duas bandas espectrais ( $\lambda=205$ e $265 \mathrm{~nm}$ ), como demonstrado na Figura $2 \mathrm{~B}$, o que estaria relacionado à formação de subprodutos decorrentes da ruptura da própria molécula do corante, sendo que o efluente obtido no final dos ciclos dessa etapa apresentava-se turvo.

Verificou-se que, apesar das oscilações de matéria orgânica no afluente, em decorrência do próprio processo industrial — tratando-se o meio de efluente "in natura" -, estas não influenciaram na remoção de DQO bruta e dissolvida, evidenciando a fácil adaptação da biomassa fúngica às condições do meio.

$\mathrm{Na}$ etapa I, a remoção média de matéria orgânica dissolvida foi 85\%, com máxima de 99\% (ciclo 16) e mínima de 70\% (ciclo C22), o que representou em termos de concentração no efluente, $23 \mathrm{mg} \cdot \mathrm{L}^{-1}$ (ciclo C16) e $561 \mathrm{mg} . \mathrm{L}^{-1}$ (ciclo C22).

Para a DQO bruta, a eficiência média de remoção para a etapa I foi de 75\%, com máxima de 94\% (ciclo 14) e mínima de 51\% (ciclo C22),
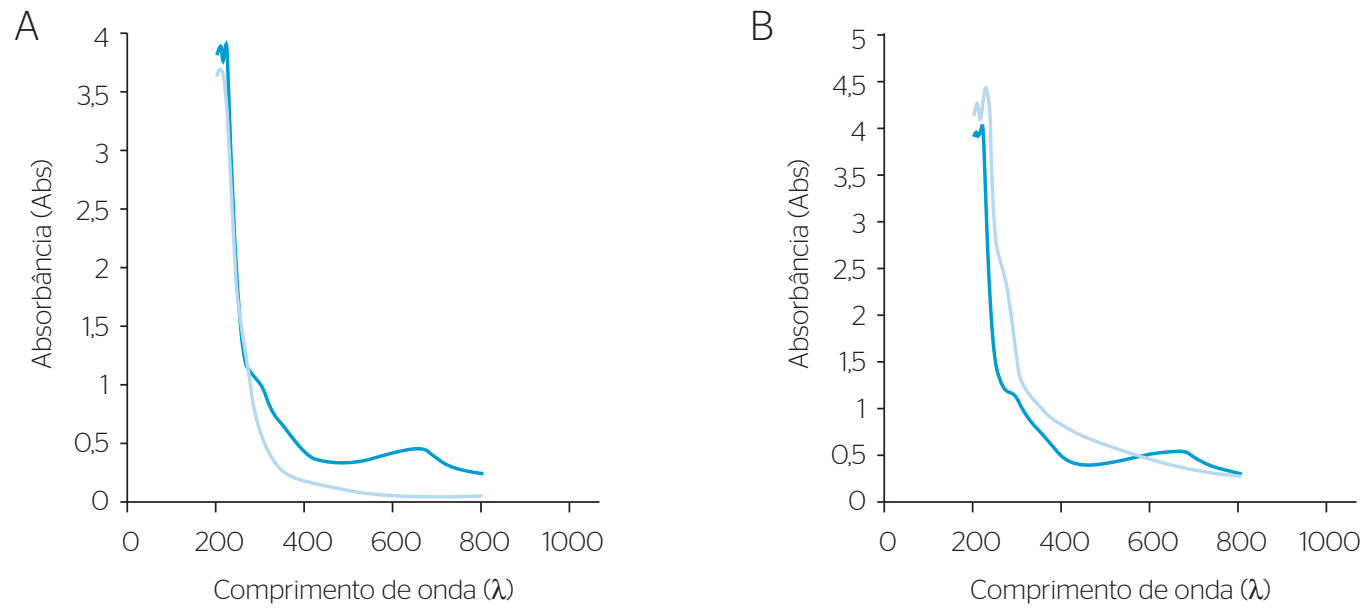

— Entrada (Abs) _ Saída (Abs)

Figura 2 - Varredura do corante Índigo Carmim no ciclo C16 (A) e ciclo 19 (B), durante a operação do reator em bateladas sequenciais na etapa I. 
resultando em termos de concentração para o efluente, $208 \mathrm{mg} . \mathrm{L}^{-1}$ (ciclo C14) e 1155 mg.L $L^{-1}$ (ciclo C22).

Nessa etapa, de modo geral, a eficiência de degradação do corante foi inferior à registrada para remoção de matéria orgânica dissolvida, sendo que, nos ciclos C2, C6, C7, C9, C17 e C18, os percentuais de remoção obtidos para o corante foram muito baixos em relação às eficiências tanto de matéria orgânica bruta quanto dissolvida, indicativo de que a maior parte da matéria orgânica removida estaria relacionada com o uso da glicose e outros constituintes da água residuária pelos micro-organismos, tendo o Índigo Carmim sido removido parcialmente.

Nos ciclos C1, C3, C5, C11, C14, C15, C23 e C24 os percentuais de eficiências de degradação do corante acompanharam os de matéria orgânica dissolvida, fato que permitiu inferir que nos ciclos mencionados houve não somente a remoção do cromóforo, mas, provavelmente, melhor assimilação de outros componentes da estrutura molecular do corante, bem como menor formação de excretas pelos fungos.

Por outro lado, nessa mesma etapa, embora nos ciclos C10, C12, C13, C21 e C22 não tenha ocorrido eficiência de remoção do corante, com aumento da concentração do Índigo Carmim no efluente ao final dos ciclos, foram registradas remoções elevadas de matéria orgânica dissolvida, respectivamente, 88; 77; 81; 84 e 70\%. Pode ter ocorrido desprendimento em maior quantidade de parte do corante que estaria adsorvido ao biofilme/material suporte, indicando que na etapa I houve instabilidade do sistema, com momentos de eficiência baixa ou nenhuma remoção de corante na maior parte da operação do RBS.

A instabilidade do sistema observada na etapa I foi atribuída ao excesso de nitrogênio, o que afeta diretamente o funcionamento do sistema enzimático e causa alterações no metabolismo secundário da célula (LEATHAM \& KIRK, 1983), inibindo a assimilação do corante pelos fungos (SWAMY \& RAMSAY, 1999).

Vahabzadeh, Mehranian e Saatari (2004) relataram que a remoção de cor é afetada pela concentração de nitrogênio amoniacal, pois a velocidade de ruptura da molécula diminui quando esse íon encontra-se presente em excesso.

A importância da fonte de nitrogênio sobre a remoção de cor e degradação do corante também foi relatada por Levin, Melignani e Ramos (2010), que apontaram para sua influência sobre a produção de enzimas lignolíticas pelos fungos Trametes trogii, Trametes villosa e Coriolus versicolor var. antarcticus, em meio mineral contendo glicose $\left(20\right.$ g.L $\left.\mathrm{L}^{-1}\right)$ e variadas fontes de nitrogênio, as quais foram utilizadas separadamente, sendo adicionadas ao meio na concentração de 0,75 g.L $\mathrm{L}^{-1}$. Verificou-se que ácido glutâmico seguido de peptona foram excelentes para a produção de maiores quantidades das enzimas laccase e manganês peroxidase, importante arsenal para a degradação de poluentes orgânicos complexos, chegando-se à produção de, respectivamente, a 1188,3 e 4,5 U.mL ${ }^{-1}$.
Senthilkumar, Perumalsamy e Janardhana Prabhu (2011) estudaram o efeito da concentração de nitrogênio sobre a degradação de água residuária têxtil sintética contendo 1 g.L.-1 de Amido Black 10 pelo fungo Phanerochaete chrysosporium. Os autores utilizaram $\mathrm{NH}_{4} \mathrm{H}_{2} \mathrm{PO}_{4}$ e $\mathrm{NH}_{4} \mathrm{Cl}$ como fonte de nitrogênio, compreendendo mistura na razão de 5:1, que foi adicionada à água residuária sintética a fim de perfazer concentrações de 0,$01 ; 0,05 ; 0,1 ; 0,5$ e $1 \%(\mathrm{w} / \mathrm{w})$. Embora se tenha constatado aumento da remoção de cor do meio com o aumento da concentração de 0,01 a 0,5\%, houve redução acentuada da remoção de cor na concentração de $1 \%$, ratificando o efeito negativo do excesso de nitrogênio sobre a remoção de cor e de corante, o qual na pesquisa mencionada também se encontrava na forma de nitrogênio amoniacal.

Niebisch et al. (2010) avaliaram o efeito de diferentes fontes de nitrogênio - nitrato de sódio, ureia, tartarato de amônia, cloreto de amônio, peptona e oxalato de amônio - , com concentrações variando de 5 a 15 g.L. $L^{-1}$, sobre a remoção de cor de meio contendo corante Azul Reativo $220\left(0,1\right.$ g. $\left.\mathrm{L}^{-1}\right)$, na presença de glicose $\left(10\right.$ g. $\left.\mathrm{L}^{-1}\right)$, por Lentinus crinitus. $\mathrm{O}$ experimento foi conduzido ao longo de 15 dias, a $28^{\circ} \mathrm{C}$, na ausência de luz, e o oxalato de amônio (10 g.L $\left.\mathrm{L}^{-1}\right)$ foi a melhor fonte de nitrogênio, resultando na maior remoção de cor, em torno de $90 \%$ ( $10^{\circ}$ dia).

Eficiências tão elevadas quanto à encontrada por Niebisch et al. (2010) também foram registradas na presente pesquisa, quando da suspensão da adição de fonte externa de nitrogênio (etapa II), com remoção máxima de Índigo Carmim, de 97\%, em apenas 48 h, em menor concentração de glicose (3 g.L $\left.\mathrm{L}^{-1}\right)$ e em maior concentração inicial do corante ( 4 a $20 \mathrm{mg} . \mathrm{L}^{-1}$ ), ainda que se trate de corantes diferentes.

Ainda na etapa II, apesar da melhora acentuada na remoção de Índigo Carmim, foi registrada diminuição da remoção de matéria orgânica. A eficiência média de DQO bruta foi de 64\%, com máxima de 90\% (ciclos C33 e C34) e mínima de 23\% (ciclo C26). Em relação à matéria orgânica dissolvida, em termos de DQO, a média de remoção alcançada nessa etapa foi $69 \%$, com máxima de $90 \%$ (ciclos 33 e 34), e mínima de 43\% (ciclo C23).

Observou-se que na etapa II ocorreu diminuição na média de remoção de DQO dissolvida em comparação com a etapa I (85\%), registrando-se percentual médio de $69 \%$. Contudo, houve aumento da eficiência média de remoção de corante, com remoção média de corante de 83\%, máxima de 97\% (ciclos C26 e C40) e mínima de 69\% (ciclo C39), o que indicou a melhor resposta do sistema após a retirada da fonte adicional de nitrogênio.

A remoção de corante em detrimento da remoção de matéria orgânica dissolvida pode ter sido ocasionada pela maior formação de subprodutos não identificados, os quais seriam decorrentes da ruptura das ligações químicas do corante em estudo e que não teriam sido efetivamente assimilados pelos micro-organismos. 
Semelhantemente, houve também a diminuição da eficiência do tratamento em relação à remoção média de matéria orgânica bruta (64\%) em comparação com a etapa I, quando foi registrada eficiência média de remoção de $75 \%$.

Assim, na etapa II, possivelmente tenha ocorrido melhor atividade enzimática, a qual antes teria sido fortemente inibida pela concentração elevada de nitrogênio amoniacal no afluente (192 mg.. $\left.\mathrm{L}^{-1}\right)$ que diminuiu para 98 mg.L $L^{-1}$. Nessa condição, ocorreu o melhor desempenho do sistema, com o alcance de maior remoção do poluente e, provavelmente, de seus subprodutos, apresentando efluente muito clarificado no final dos ciclos.

$\mathrm{Na}$ referida etapa, o efluente apresentou os menores valores de $\mathrm{pH}$, entre 4 e 7,5, cujo valor médio foi de 5,6, sendo que nessa condição ocorre maior produção de enzimas, conforme relatado por Spier (2005), o qual frisou ainda que a produção de enzimas atinge seu ótimo em valores de $\mathrm{pH}$ em torno de 5.

$\mathrm{Na}$ etapa I, a adição de 3 g.L $\mathrm{L}^{-1}$ de glicose teria resultado na produção de ácidos orgânicos (ZNAD; MARKOS; BALES, 2004) que devem ter sido prontamente consumidos do meio pelos micro-organismos, $\mathrm{O}$ que, aliado ao excesso de compostos com nitrogênio adicionados na água residuária têxtil in natura, como nitrato de sódio e sulfato de amônio, contribuiu para a elevação do $\mathrm{pH}$ do meio nos ciclos operacionais. Sabe-se que esses compostos regulam equilíbrio metabólico da célula fúngica, variando de acordo com suas necessidades (SINGH, 2006).

Neste trabalho, a espécie Aspergillus niger AN 400, utilizada como inóculo no reator em bateladas sequenciais, encontrava-se no meio ao final da operação das etapas I e II, sendo que, na etapa I, foi registrado maior número de colônias de bactérias em relação às de fungos, $20 \times 10^{7}$ e $15 \times 10^{7}$ unidades formadoras de colônia por $\mathrm{mL}$ (UFC. $\mathrm{mL}^{-1}$ ), respectivamente, resultando em relação de 1:0,75 (bactérias:fungos).

Já na etapa II, o número de colônias de fungos foi de $157 \times 10^{3} \mathrm{UFC} \cdot \mathrm{mL}^{-1}$, inferior ao valor encontrado na etapa $\mathrm{I}\left(17 \times 10^{7} \mathrm{UFC} / \mathrm{mL}\right)$, porém superior à população de bactérias verificada para essa mesma etapa (etapa II), a qual foi de $90 \times 10^{3}$ UFC. $\mathrm{mL}^{-1}$. Assim, na etapa II foi obtida a relação bactérias:fungos de 0,57:1, indicando que na condição de menor concentração de nitrogênio amoniacal ( $\left.98 \mathrm{mg} \cdot \mathrm{L}^{-1}\right)$, os fungos tiveram melhores condições de se sobressair em relação às bactérias e de metabolizar os substratos presentes, provavelmente, pela não inibição de seu sistema enzimático, fato este que teria ocorrido na etapa I, devido ao excesso de nitrogênio.

Ainda, a concentração na qual o antibiótico foi usado na presente pesquisa não inibiu o crescimento da população de bactérias. Porém, a população bacteriana não cresceu predominando no meio, ao ponto de exercer efeito negativo sobre os fungos, fato que poderia ocasionar perda da eficiência do sistema, motivado também pela repressão do sistema enzimático fúngico (YANG et al., 2009).
Contudo, de acordo com Lopes et al. (2011), é importante ressaltar que o tratamento biológico aplicado ao efluente não visa à operação de reatores sob condições assépticas, pois no tratamento de águas residuárias, diferentemente da indústria de fermentação, isto é impensável. Além do mais, ainda segundo os autores, a ação em conjunto de fungos e bactérias é favorável ao processo de biorremediação, pois estes são os maiores decompositores encontrados na natureza e são responsáveis pela mineralização de vários poluentes, muitos deles com maior eficiência de remoção quando metabolizados em culturas mistas (GRIFFIN, 1994; HAI et al., 2008; SINGH, 2006).

De acordo com Yang et al. (2009), fungos e bactérias podem estabelecer uma relação de simbiose, na qual os fungos atuam na ruptura de moléculas complexas, as quais as bactérias presentes no meio não são capazes de utilizar ao ponto de se obter um grau de mineralização elevado, e então os subprodutos oriundos da ruptura dessas moléculas estariam disponíveis para serem utilizados por fungos e bactérias que atuariam em conjunto no tratamento do despejo.

\section{CONCLUSÕES}

Na presença de concentração elevada de amônia (192 mg.L $\left.\mathrm{L}^{-1}\right)$, houve eficiência baixa de remoção de corante e de matéria orgânica e, nessa condição, maior acúmulo de subprodutos no meio, decorrentes da utilização das fontes de carbono, com grande persistência do benzeno oriundo da ruptura da molécula do Índigo Carmim.

Quando a fonte adicional de nitrogênio deixou de ser adicionada ao meio, ocorreu melhor desempenho de sistema e maior número de colônias de fungos em relação ao de bactérias, favorecendo a não repressão do sistema enzimático fúngico, importante na degradação dos poluentes.

Assim, na etapa II, marcada pela supressão da fonte adicional de nitrogênio, a população de fungos predominou no reator indicando que os mesmos teriam encontrado melhores condições de crescimento e de assimilação dos substratos, sendo importante ressaltar a necessidade de otimizar o sistema e a realização de mais estudos sobre mecanismos que propiciem obter maior grau de mineralização da molécula do corante.

\section{AGRADECIMENTOS}

Os autores agradecem a Deus, que nos permitiu chegar até aqui; ao Conselho Nacional de Pesquisa (CNPq) pela concessão das bolsas de iniciação científica e financiamento da pesquisa pelo Processo no. 475831/2010-1 e à Coordenação de Aperfeiçoamento de Pessoal de Nível Superior (CAPES) pela concessão da bolsa de mestrado. 


\section{REFERÊNCIAS}

ALVES, F.C. (2013) Estudo dos processos de adsorção utilizando argilas como adsorventes para remoção do corante verde malaquita. Dissertação (Mestrado em Agroquímica), Universidade Federal de Lavras, Minas Gerais.

ANASTÁCIO FERRAZ, E.R. (2008) Comparação da mutagenicidade dos azo corantes Disperse Red 1, Disperse Orange 13 e Disperse Red 13 utilizando o teste de mutagenicidade Salmonella. Dissertação (Mestrado). Universidade de São Paulo, Ribeirão Preto.

ANJANEYULU, Y.; CHARY, N.S.; RAJ, D.S.S. (2005) Descolourization of industrial effluents - available methods and emerging technologies - a review. Reviews in Environmental Science and Biotechnology, v. 4, n. 4, p. 245-273.

APHA - AMERICAN PUBLIC HEALTH ASSOCIATION. (2005) Standard methods for the examination of water and wastewater. 21st edition. Washington: APHA.

BANAT, I.M.; NIGAM, P.; SINGH, D.; MARCHANT, R. (1996) Microbial decolorization of textile-dyecontaining effluents: a review. Bioresource Technology, v.58, n.3, p.217-227.

BOLZON, L.B. (2007) $\mathrm{N}_{2} b_{2} \mathrm{O}_{5}$ como fotocatalizador para a degradação de índigo carmina. Dissertação (Mestrado em Química), Universidade de Brasília, Brasília.

CHAVES, K.O.; MONTEIRO, C.R.L.; MUNIZ, C.R.; GOMES, R.B.; BUARQUE, H.L.B. (2008) Adsorção de índigo carmim em biomassas mortas de Aspergillus niger. Engenharia Sanitária e Ambiental, v. 13, n. 4, p. 351-355.

COULIBALY, L.; GOURENE, G.; AGATHOS, S.N. (2OO3) Utilization of fungi for biotreatment of raw wastewaters. African Journal of Biotechnology, v. 2, n. 12, p. 620-630.

COUTO, R.S. (2009) Dye removal by immobilised fungi. Biotechnology Advances, v. 27, n. 3, p. 227-235.

DEBRASSI, A.; LARGURA, M.C.T.; RODRIGUES, C.A. (2011) Adsorção do corante vermelho congo por derivados da o-carboximetilquitosana hidrofobicamente modificados. Química Nova, v. 34, n. 5, p. 764-770.

GIANFREDA, L. \& RAO, M.A. (2004) Potential of extra cellular enzymes in remediation of polluted soils: a review. Enzyme and Microbial Technology, v. 35, n. 4, p. 339-354.

GRIFFIN, D.H. (1994) Fungal physiology. 2nd ed. New York: Wiley-Liss. $458 \mathrm{p}$.

HAI, F.I; YAMAMOTO, K.; NAKAJIMA, F.; FUKUSHI, K. (2008) Removal of structurally different dyes in submerged membrane fungi reactorbiosorption/PAC-adsorption and biodegradation. Journal of Membrane Science, v. 325, n. 1, p. 395-403.

ISIK M.; SPONZA, D.T. (2005) Effects of alkalinity and co-substrate on the performance of an upflow anaerobic sludge blanket (UASB) reactor through decolonization of Congo Red azo dye. Bioresource Technology, v. 96, n. 5, p. 633-643.
KHELIFI, E.; AYED, L.; BOUALLAGUI, H.; TOUHAMI, Y.; HAMDI, M. (2009) Effect of nitrogen and carbon sources on Indigo and Congo red decolourization by Aspergillus alliaceus strain 121C. Journal of Hazardous Materials, v. 163, n. 2-3, p. 1056-1062.

KILIÇ, N.K.; NIELSEN, J.L.; YÜCE, M.; DÖNMEZ, G. (2O07) Characterization of a simple bacterial consortium for effective treatment of wastewaters with reactive dyes and $\mathrm{Cr}(\mathrm{VI})$. Chemosphere, v. 67, n. 4, p. 826-831.

LEATHAM, G.F.; KIRK, T.K. (1983) Regulation of ligninolytic activity by nutrient nitrogen in white-rot basidiomycetes. FEMS Microbiology Letters, v. 16, n. 1, p. 65-67.

LEVIN, L.; MELIGNANI, E.; RAMOS, A.M. (2O10) Effect of nitrogen sources and vitamins on ligninolytic enzyme production by some white-rot fungi: dye decolorization by selected culture filtrates. Bioresource Technology, v. 101, n. 12, p. 4554-4563.

LOPES, M.S.S.; OLIVEIRA, P.C.C; ANDRADE, M.V.F;; ARAÚJO, R.S. MARINHO, G.; RODRIGUES, K. (2011) Remoção de macronutrientes de efluente da indústria de castanha de caju por uso de reator aeróbio em batelada com inóculo fúngico. Engenharia Sanitária e Ambiental, v. 16, n. 1, p. 17-26.

NIEBISCH, C.H.; MALINOWSKI, A.K.; SCHADECK, R.; MITCHELL, D.A. KAVA-CORDEIRO, V.; PABA, J. (2010) Decolorization and biodegradation of reactive blue 220 textile dye by Lentinus crinitus extracellular extract. Journal of Hazardous Materials, v. 180, n. 1-3, p. 316-322.

QUINTERO, L.; CARDONA, S. (2010) Tecnologías para la decoloración de tintes índigo e índigo carmín. Revista de la Facultad de Minas de la Universidad Nacional de Colombia, v. 77, n. 162, p. 371-386.

RODRIGUES, K.; SILVA, K. M. L.;SILVA, G. M. M.; LIMA, P. C. C.; WANDERLEY, C. R. P.; SILVA, G. M. (2011) Remoção de corante por uso de Aspergillus niger AN400 em reator em bateladas sequenciais. Química Nova, v. 34, n. 7, p. 1119-1123.

SANGHI, R.; DIXIT, A.; VERMA, P.; PURI, S. (2009) Design of reaction conditions for the enhancement of microbial degradation of dyes in sequential cycles. Journal of Environmental Sciences, v. 21, n. 12, p. 1646-1651.

SANGHI, R.; DIXIT, A.; GUHA, S. (2006) Sequential batch culture studies for the decolorization of reactive dye by Coriolus versicolor Bioresource Technology, v. 97, n. 3, p. 396-400.

SARON, C. \& FELISBERTI, M.I. (2006) Ação de colorantes na degradação e estabilização de polímeros. Química Nova, v. 29, n. 1, p. 124-128.

SENTHILKUMAR, S.; PERUMALSAMY, M.; JANARDHANA PRABHU, $H$ (2014) Decolourization potential of white-rot fungus Phanerochaete chrysosporium on synthetic dye bath effluent containing Amido Black 10B. Journal of Saudi Chemical Society, v. 18, n. 6, p. 845-853.

SINGH, H. (2006) Mycoremediation: fungal bioremediation. Canada Wiley. $617 \mathrm{p}$. 
SPIER, M.R. (2005) Produção de enzimas amiloliticas fúngicas alfa-amilase e amiloglucosidase por fermentação no estado sólido. Dissertação (Mestrado em Tecnologia de Alimentos), Universidade Federal do Paraná, Curitiba.

SWAMY, J. \& RAMSAY, J.A. (1999) Effects of glucose and $\mathrm{NH}_{4}^{+}$ concentrations on sequential dye decoloration by Trametes versicolor. Enzyme and Microbial Technology, v. 25, n. 3-5, p. 278-284.

VAN DER ZEE, F. \& VILLAVERDE, S. (2005) Combined anaerobic-aerobic treatment of azo dyes: a short review of bioreactor studies. Water Research, v. 39, n. 8, p. 1425-1440.

VAHABZADEH, F.; MEHRANIAN, M.; SAATARI, A.R. (2004) Color removal ability of Phanerochaete chrysosporium in relation to lignin peroxidase and manganese peroxidase produced in molasses wastewater. World Journal of Microbiology and Biotechnology, v. 20, p. 859-864.
YANG, Q.; LI, C.; LI H.; LI, Y.; YU, N. (2009) Degradation of synthetic reactive azo dyes and treatment of textile wastewater by a fungi consortium reactor. Biochemical Engineering Journal, v. 43, n. 3, p. 225-230

WANG, B.E. \& HU, Y.Y. (2008) Bioaccumulation versus adsorption of reactive dye by immobilized growing Aspergillus fumigatus beads. Journal of Hazardous Materials, v. 157, n. 1, p. 1-7.

ZNAD, H.; MARKOS, J.; BALES, V. (2004) Production of gluconic acid from glucose by Aspergillus niger: growth and non-growth conditions. Process Biochemistry, v. 39, n. 11, p. 1341-1345.

ZANONI, M.V.B. \& CARNEIRO, P.A. (2001) O descarte dos corantes têxteis. Ciência Hoje, v. 29, p. 61-65. 